\title{
Effect of Preoperative Abdominal Training on Abdominal Muscles Strength Outcomes after Ventral Hernia Repair
}

\author{
MOHAMED G. AHMED, M.Sc.*; SALAH A. MOHAMED, M.D.**; WALID A. ABOU EL-NAGA, Ph.D.* and \\ MOHAMED M. EL-KABLAWY, Ph.D.* \\ The Departments of Physical Therapy for Surgery, Faculty of Physical Therapy* and Surgery, Faculty of Medicine**, \\ Cairo University
}

\begin{abstract}
Background: Hernias are caused by a weakness in the abdominal wall along with increased intra-abdominal pressure and poor wound healing. Ventral (incisional) hernias usually result from a weakness in the abdominal wall after abdominal surgery, especially in the obese patient.

Aim of Study: To investigate the effect of pre-operative abdominal training on abdominal muscle strength outcomes after ventral hernia repair by using isokinetic dynamometer as a method of evaluation.

Methods: 30 patients their age ranged between 20-45 years with ventral hernia, they were directed to operative hernia repair. The patients were randomly divided into two groups: Group (A) (control group) and Group (B) (study group). Isokinetic dynamometer was used to evaluate abdominal muscle strength at 3 occasions, first (initial assessment), second (pre-operative assessment), and third (6 months postoperative assessment). For Group (A) (control group); they were instructed to presume their activities of daily living preoperatively. For Group (B) (study group); they received selective abdominal training program for $30 \mathrm{~min} .3$ times per week for 6 weeks pre-operatively.

Results: The result showed that there was a significant increase in abdominal muscle strength post-operatively in study (abdominal training) group compared to control group.

Conclusion: It was concluded that pre operative abdominal muscle training was effective for strengthening abdominal muscles after ventral hernia repair.
\end{abstract}

Key Words: Ventral hernia-Abdominal training - Isokinetic.

\section{Introduction}

HERNIATION refers to protrusion of an organ or tissue through an opening that may be natural or caused by a tear in the abdominal wall. Ventral abdominal hernia is a commonly acquired condition

Correspondence to: Dr. Mohamed G. Ahmed, The Department of Physical Therapy for Surgery, Faculty of Physical Therapy, Cairo University in small ruminants caused by the migration of viscera through a tear in the abdominal wall [1]

Although the repair of ventral abdominal wall hernias is one of the most commonly performed operations, many aspects of their treatment are still under debate or poorly studied [2] .

The European Hernia Society (EHS) Board agreed on a new classification. EHS classification defines the location of hernia with $\mathrm{L}$ (lateral), $\mathrm{M}$ (medial), and $\mathrm{F}$ (femoral). The size of hernia is indicated with 1 ( $<=1$ finger), 2 (1-2fingers), and 3 (=>3 fingers) [3] .

Incisional hernia is the most frequent surgical complication after laparotomy. Up to $30 \%$ of all patients undergoing laparotomy develop an incisional hernia. Although significant improvements have been achieved in the field of incisional hernia operative technique and the use of prosthetic materials, recurrence rates remain high at $32 \%$ to $63 \%[4]$.

The origin of traumatic suprapubic hernias is often through a ruptured rectus muscle at or near its insertion to the pubic bone. In contrast, incisional suprapublic hernias develop as result of apical public osteotomy or iatrogenic detachment of a suprapubic defect [5].

The laparoscopic approach for the repair of ventral/incisional hernias was first reported in the early 1990. Since that time the technique has evolved into an accepted repair for the management of ventral/incisional hernias [6].

Laparoscopic Ventral Hernia Repair (LVHR) has gained acceptance as a safe and effective alternative to Open Ventral Hernia Repair (OVHR), 
resulting in reduced patient complications and hospital stays [7].

Recurrence rates vary between 4 and $32 \%$ after OVHR and between 3 and 15\% after LVHR. Data concerning the patient follow-up strategy are often incomplete and imprecise, regarding the criteria used (clinical, CT scan or questionnaire) to assess recurrence [8].

Surgery is a great stressor to patients and causes large physiological changes. Pre-operative physical functioning appears to be an important predictor of morbidity and mortality in patients that undergo various types of surgery. After Major Abdominal Surgery (MAS), $35 \%$ of the patients experience post-operative complications [9].

Postsurgical immobilization has long been suspected as the culprit for abdominal muscle atrophy, especially for muscles not damaged by the surgery [10].

Abdominal surgery causes a flaw in the abdominal wall. This flaw can create an area of weakness in which hernia may develop. This occurs after 2 to $10 \%$ of all abdominal surgeries [11].

Use of exercise prior to an acute stressor such as surgery has emerged as a viable perioperative risk-reduction strategy. This concept, known as prehabilitation, was first used in sports medicine to reduce the impact of an injury prior to its occurrence [12].

The abdominal muscles have a role to play in all movement. This makes perfect sense considering the higher number of nerve innervations into these muscles. It indicates that these muscles can do more things and respond to a great variety of movement [13].

Core stability exercise is an important component of rehabilitation, that consists of three subsystems: The passive subsystem (which includes bone, ligament and joint capsule), the active subsystem (which includes muscle and tendons), and the neural subsystem (which consists of the central nervous system and peripheral nervous system) [14]

Crunches on a Swiss ball with added elastic resistance induces high rectus abdominis activity accompanied by low hip flexor activity [15] .

The Biodex ${ }^{\circledR}$ dynamometer studies muscle strength during isokinetic movement, which is a movement with a constant angular velocity (given by the dynamometer) within a certain range against a changing resistance, given by the subject [16]

Isokinetic dynamometershasbeen established as the accepted standard for the quantification of muscle strength by measuring joint moments in both static (isometric) and dynamic conditions [17].

\section{Subjects and Methods}

This study was carried out on thirty patients presented with ventral hernia, pre-operatively, from Kasr Al-Aini University Hospital during 2017. All of them were diagnosed with ventral hernia and consulted to surgical hernia repair, their ages were ranged from 20-45 years old. Patients participated in this study were 24 females and 6 males.In this study, the patients were randomly assigned into two equal groups. Group A (control group): Consisted of 15 subjects ( 12 females and 3 males) and were presuming in normal activities of daily livingwithout abdominal training procedures. Group B (study group): Consisted of 15 patients (12 females and 3 males) who received selective abdominal training program for $30 \mathrm{~min} .3$ times per week for 6 weeksbefore surgery.

\section{A- Evaluation procedures:}

Measurement of abdominal muscle torque', the torque of abdominal muscle measured by using biodex isokinetic system. The evaluation procedures were conducted at Faculty of Physical Therapy, Cairo University, laboratory of Isokinetic 3 . Each patient was allowed to sit on the adjustable seat of the Biodex isokinetic dynamometer system. The subject lied supine on a movable bench in a bent knee position. The lever arm of the isokinetic dynamometer set at 180 degrees (horizontal with the ground) and the padded extension was placed just below the nipple line on the lower third of the sternum. Each subject given several practice trials to make sure the position of the lever arm will be comfortable on their chest. Subjects then performed five isometric contractions, with approximately 30 seconds between each repetition. The average torque for the highest two repetitions used in the analysis.

\section{B-Treatment procedures:}

An abdominal exercise training program was designed and graduated as follow:

\section{1- Flexibility training exercises:}

All patients received the following manual therapy interventions administered by the same physical therapist: Soft tissue mobilization techniques to the lumbar and hip regions, joint mobilization/manipulation techniques to the pelvis, SIJ, 
and/or hips, neuromuscular reeducation, and manual stretching. Each mobilization/manipulation was applied for 30 seconds, at a rate of approximately 1 mobilization every 1 to 2 seconds, followed by a 30 -second rest.

2- Selective abdominal muscles strengthening exercises training:

\section{-Activation of rectus abdominis:}

The patients were instructed to curl up trunk and raise lower limbs in a low-intensity isometric contraction for 10 seconds, the resistance was provided by restraining belts attached to the patients.

\section{- Posterior pelvic tilt:}

The therapist asked the patient to start the motion by drawing the pubic symphysis towards the umbilicus with emphasis on anterior musculature contracting. The fingers should feel the transverses abdominis contract equally on each side, the rib cage should depress and the lumbar spine should flatten with little effort applied.

\section{- Rotational planks:}

The initial starting position of the patient was prone while body held suspended on flexed elbow and feet. The therapist asked the patient to hold lumbar spine in neutral position while isometrically contract the transverse abdominis Fig. (1).

\section{- Abdominal crunch on Swiss ball with elastic resistance:}

The patient was asked to lie on the Swiss ball and then walk the feet away while simultaneously going down into a lying position, allowing the ball to stop at the lumbar spine area of the lower back. The feet were placed approximately 2 feet apart while the knees were bent at a 90 degree angle for increased base of support and adequate stability and balance. The hands were placed at shoulder level grasping the elastic resistance handles-the elastic tubing was stretched to double resting length at this point Fig. (2).

\section{Statistical analysis:}

Descriptive statistics and $t$-test was conducted for comparison of the mean age, between both groups. $t$-test was conducted for comparison of pre and post-operative mean values of abdominal muscles peak torque between control and study groups. Paired $t$-test for comparison between pre and posttreatment mean values of abdominal muscles peak torque in each group. ANOVA with repeated measures was conducted for comparison between preoperative, post-exercise and post-operative mean values of abdominal muscles peak torque.

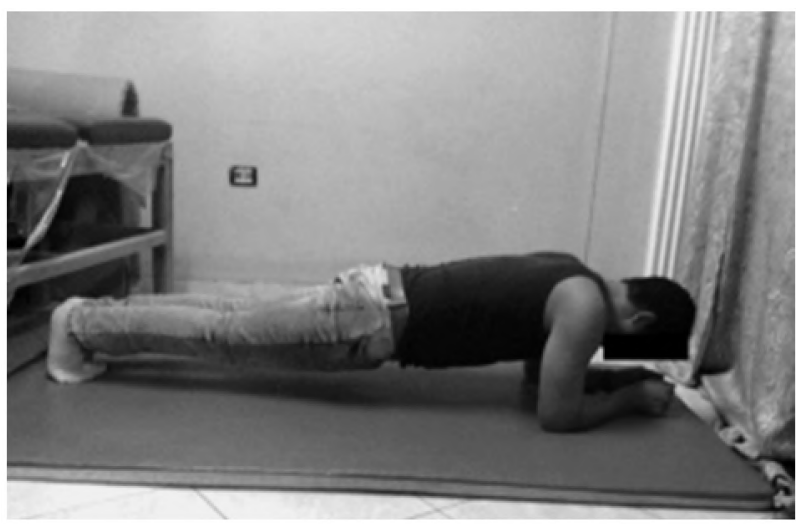

Fig. (1): Rotational planks (from prone).

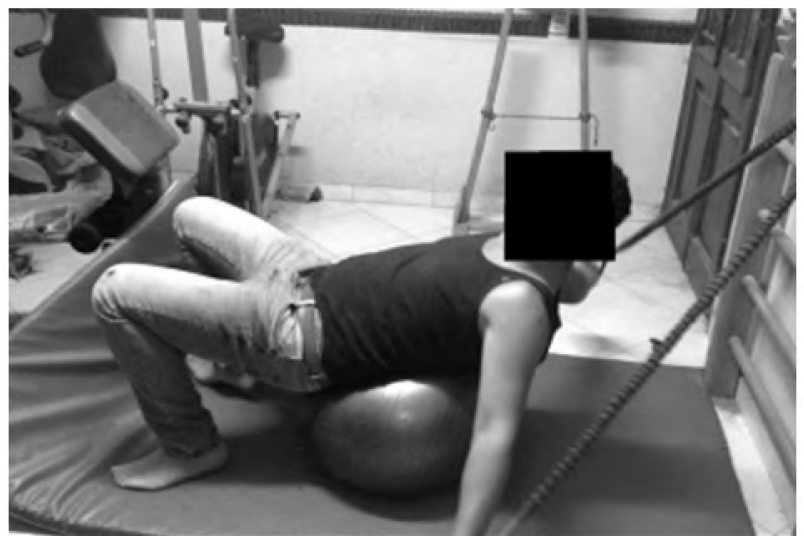

Fig. (2): Abdominal crunch on Swiss ball with elastic resistance.

\section{Results}

I- Initial assessment, pre-operative and postoperative mean values of abdominal muscles peak torque of control group:

The mean \pm SD abdominal muscles peak torque of control group at initial assessment was 35.09 $\pm 7.33 \mathrm{Nm}$, while pre-operative was $33.97 \pm 6.78 \mathrm{Nm}$, and post-operative was $30.05 \pm 8.94 \mathrm{Nm}$. Comparison between initial assessment, pre-operative and postoperative revealed a significant difference in abdominal muscles peak torque between the threetime intervals ( $p=0.002)$ (Table 1), Fig. (3).

\section{II- Initial assessment, pre-operative and post- operative mean values of abdominal muscles peak torque of study group:}

The mean \pm SD abdominal muscles peak torque of study group at initial assessment was $34.39 \pm$ $5.92 \mathrm{Nm}$, while pre-operative was $45.89 \pm 9.53 \mathrm{Nm}$, and post-operative was $41.3 \pm .89 \mathrm{Nm}$. Comparison between initial assessment, pre-operative and postoperative revealed a significant difference in abdominal muscles peak torque between the threetime intervals ( $p=0.0001$ ) (Table 2), Fig. (4). 


\section{III- Post-operative mean values of abdominal muscles peak torque of both groups (control and study):}

The mean \pm SD abdominal muscles peak torque pre-operative of the control group was $33.97 \pm 6.78$ $\mathrm{Nm}$ and that of the study group was $45.89 \pm 9.53$ $\mathrm{Nm}$. The mean difference between both groups was $-11.92 \mathrm{Nm}$. There was a significant increase in the abdominal muscle peak torque in the study group compared with that of the control groups pre-operative ( $p=0.0001$ ) (Table 3), Fig. (5).

The mean \pm SD abdominal muscles peak torque post-operative of the control group was $30.05 \pm 8.94$ $\mathrm{Nm}$ and that of the study group was $41.3 \pm 8.89 \mathrm{Nm}$. The mean difference between both groups was $-11.25 \mathrm{Nm}$. There was a significant increase in the abdominal muscle peak torque in the study group compared with that of the control groups postoperative $(p=0.002)$ (Table 3), Fig. (5).

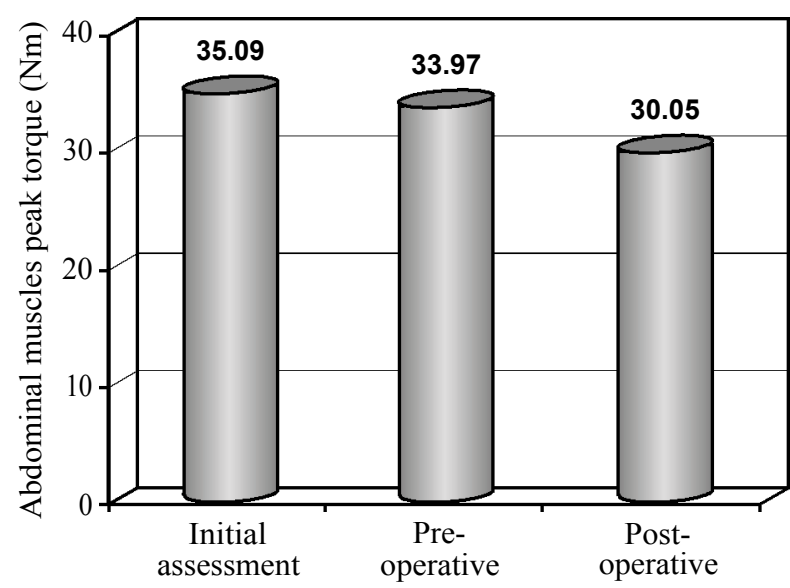

Fig. (3): Initial assessment, pre-operative and post-operative mean values of abdominal muscles strength of control group.

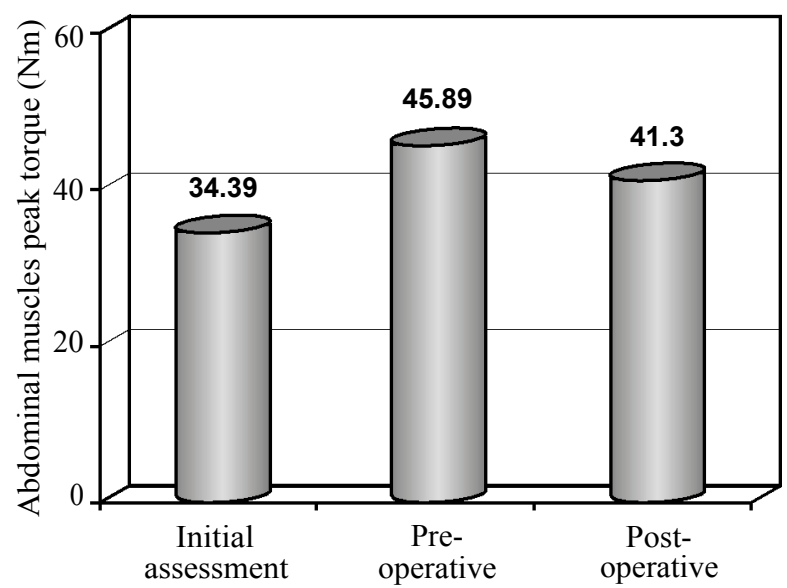

Fig. (4): Initial assessment, pre-operative and post-operative mean values of abdominal muscles strength of study group.

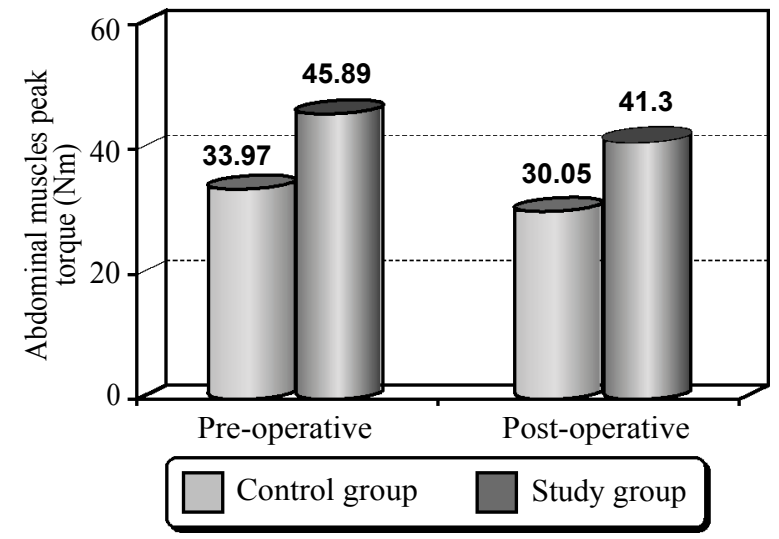

Fig. (5): Pre and post-operative mean values of abdominal muscles strength of control and study groups.

Table (1): Comparison between initial assessment, preoperative and post-operative mean values of abdominal muscles peak torque of control group.

Abdominal muscles peak torque $(\mathrm{Nm})$

\begin{tabular}{lcccccc}
\hline & $\overline{\mathrm{X}} \pm \mathrm{SD}$ & & $\begin{array}{c}\text { F- } \\
\text { value }\end{array}$ & $\begin{array}{c}p- \\
\text { value }\end{array}$ & $\mathrm{Sig}$ \\
\cline { 1 - 5 } $\begin{array}{l}\text { Initial } \\
\text { assessment }\end{array}$ & $\begin{array}{c}\text { Pre- } \\
\text { operative }\end{array}$ & $\begin{array}{c}\text { Post- } \\
\text { operative }\end{array}$ & & & \\
\hline $35.09 \pm 7.33$ & $33.97 \pm 6.78$ & $30.05 \pm 8.94$ & 14.14 & 0.002 & $\mathrm{~S}$ \\
\hline
\end{tabular}

Multiple comparison (Bonferroni test)

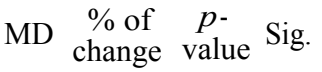

$\begin{array}{llllll}\text { Initial assessment vs. pre-operative } & 1.12 & 3.19 & 0.01 & \mathrm{~S}\end{array}$ $\begin{array}{llllll}\text { Initial assessment vs. post-operative } & 5.04 & 14.36 & 0.001 & \mathrm{~S}\end{array}$ $\begin{array}{lllll}\text { Pre-operative vs. post-operative } & 3.92 & 11.53 & 0.02 & \mathrm{~S}\end{array}$

\begin{tabular}{lll}
\hline $\mathrm{X}$ & $:$ Mean. & $p$-value : Probability value. \\
$\mathrm{SD}$ & $:$ Standard Deviation. & $\mathrm{S} \quad:$ Significant.
\end{tabular}

MD : Mean Difference.

Table (2): Comparison between initial assessment, preoperative and post-operative mean values of abdominal muscles peak torque of study group.

\begin{tabular}{|c|c|c|c|c|c|c|}
\hline \multicolumn{4}{|c|}{ Abdominal muscles peak torque $(\mathrm{Nm})$} & \multirow{3}{*}{$\begin{array}{c}\text { F- } \\
\text { value }\end{array}$} & \multirow{3}{*}{$\begin{array}{c}p- \\
\text { value }\end{array}$} & \multirow{3}{*}{ Sig } \\
\hline \multicolumn{4}{|c|}{$\overline{\mathrm{X}} \pm \mathrm{SD}$} & & & \\
\hline $\begin{array}{l}\text { Initial } \\
\text { assessment }\end{array}$ & Pre- & \multicolumn{2}{|c|}{$\begin{array}{c}\text { Post- } \\
\text { operative }\end{array}$} & & & \\
\hline \multirow[t]{3}{*}{$34.39 \pm 5.92$} & $45.89 \pm 9.53$ & 41 . & 8.89 & 61.95 & 0.001 & $\mathrm{~S}$ \\
\hline & & \multicolumn{5}{|c|}{$\begin{array}{l}\text { Multiple comparison } \\
\text { (Bonferroni test) }\end{array}$} \\
\hline & & MD & \multicolumn{2}{|c|}{$\begin{array}{l}\% \text { of } \\
\text { change }\end{array}$} & $\begin{array}{c}p- \\
\text { value }\end{array}$ & Sig. \\
\hline \multicolumn{2}{|c|}{$\begin{array}{l}\text { Initial assessment vs. } \\
\text { pre-operative }\end{array}$} & -11.5 & 33.4 & & 0.0001 & $\mathrm{~S}$ \\
\hline \multicolumn{2}{|c|}{$\begin{array}{l}\text { Initial assessment vs. } \\
\text { post-operative }\end{array}$} & -6.91 & 20.0 & & 0.0001 & $\mathrm{~S}$ \\
\hline \multicolumn{2}{|c|}{$\begin{array}{l}\text { Pre-operative vs. } \\
\text { post-operative }\end{array}$} & 4.59 & 10 & & 0.0001 & $\mathrm{~S}$ \\
\hline
\end{tabular}

\begin{tabular}{l}
\hline $\mathrm{x}:$ Mean. \\
SD : Standard Deviation.
\end{tabular}


Table (3): Comparison of pre and post-operative mean values of abdominal muscles peak torque between control and study groups.

\begin{tabular}{lcccccc}
\hline $\begin{array}{l}\text { Abdominal muscles } \\
\text { peak torque }(\mathrm{Nm})\end{array}$ & $\begin{array}{c}\text { Control group } \\
\mathrm{X} \pm \mathrm{SD}\end{array}$ & $\begin{array}{c}\text { Study group } \\
\mathrm{X} \pm \mathrm{SD}\end{array}$ & $\mathrm{MD}$ & $t$-value & $p$-value & Sig. \\
\hline Pre-operative & $33.97 \pm 6.78$ & $45.89 \pm 9.53$ & -11.92 & -3.94 & 0.0001 & $\mathrm{~S}$ \\
Post-operative & $30.05 \pm 8.94$ & $41.3 \pm 8.89$ & -11.25 & -3.45 & 0.002 & $\mathrm{~S}$ \\
\hline$\overline{\mathrm{X}}:$ Mean. & $\mathrm{SD} \quad:$ Standard Deviation. & \multicolumn{2}{c}{$p$-value : Probability value. } \\
$\mathrm{MD}:$ Mean Difference. & \multicolumn{2}{c}{-value : Unpaired $t$-value. } & $\mathrm{S} \quad$ Significant.
\end{tabular}

\section{Discussion}

Ventral hernia repairs continue to have high recurrence rates. The surgical literature is lacking data assessing the time trend to hernia recurrence after ventral hernia repairs and whether over time the recurrence rates change with laparoscopic technique compared to open repairs. Thus treatment that aims to reducing hernia recurrence after ventral hernia repairs is important for humanitarian and ethical reasons, but may also have economic implication as recurrence may contribute to prolonged need for surgical repair. However, little information is available about the effect of pre-operative abdominal strengthening exercise training and its outcomes post-operatively [18].

The results of the present study were consistent with Singh et al., [19] who aimed to determine the feasibility of a supervised presurgical exercise intervention in patients with rectal cancer prior to rectal resection. Twelve patients volunteered to undertake twice-weekly aerobic and resistance exercise for $\sim 16$ weeks prior to surgery. At baseline, presurgery, and $\sim 8$ weeks postsurgery, muscle strength and physical performance, body composition, quality of life, and fatigue were assessed. They concluded that: Presurgical exercise is feasible, leading to modest improvements in some outcomes despite chemoradiation treatment. The detrimental effects of surgery were evident, especially in relation to lean mass. As such, exercise may facilitate recovery by enhancing pre-surgery physical reserve capacity, thereby providing a buffer to declines following surgery.

The results of the present study were agreed with Strigård et al., [20] who aimed to investigate the relationship between the area of the abdominal wall defect and abdominal wall muscle strength measured by the validated BioDex system together with a back/abdominal unit. Fifty-two patients with giant ventral hernia underwent CT scan, clinical measurement of hernia size and BioDex measurement of muscle strength prior to surgery. The areas of the hernia derived from CT scan and from clin- ical measurement were compared with BioDex forces in the modalities extension, flexion and isometric contraction. The hernia area calculated from clinical measurements correlated to abdominal muscle strength measured with the Biodex for all modalities ( $p$-values $0.015-0.036)$. This study of patients with a giant ventral hernia reveals an inverse proportional relationship between the hernia area and abdominal wall muscle strength.

The results of the present study were consistent with Moran et al., [21] who concluded that Prehabilitation consisting of inspiratory muscle training, aerobic exercise, and/or resistance training can decrease all types of postoperative complications after intra-abdominal operations, therefore prehabilitation appears to be beneficial in decreasing the incidence of postoperative complications; however, more high-quality studies are needed to validate its use in the pre-operative setting.

The results of the present study were consistent with Pouwels et al., [22] who concluded that Preoperative Exercise Therapy (PET) exerts beneficial effects on physical fitness and postoperative outcome measures. Therefore, there is increasing need for multicenter randomized trials with specifically designed PET programs and a carefully selected patient population to strengthen current evidence.

The results of the present study were supported by Valkenet et al., [23] who concluded that preoperative exercise therapy can be effective for reducing post-operative complication rates and length of hospital stay after cardiac or abdominal surgery. More research on the utility of pre-operative exercise therapy and its long-term effects is needed as well as insight in the benefits of using risk models.

The results of the present study were consistent with Gunnarsson et al., [24] who aimed to evaluate the reliability and external validity of abdominal wall strength measurement for patients with giant ventral hernia using the Biodex System with a back abdomen unit. Ten healthy volunteers and ten 
patients with ventral hernias exceeding $10 \mathrm{~cm}$ were recruited. Test-retest reliability, both with and without girdle, was evaluated by comparison of measurements at two test occasions 1 week apart. Reliability was calculated by the Interclass Correlation Coefficients (ICC) method. It was concluded that Measurement of abdominal muscle function using the Biodex System is a reliable and valid method to assess this important patient-related endpoint.

The results of the present study were also supported by Den Hartog et al., [16] who aimed to compare the strength of the trunk flexors between patients who underwent repair for incisional hernia and a control group, and to compare trunk flexion after two kinds of operative techniques for incisional hernias with and without approximation of the rectus abdominis muscles. The trunk flexion of 30 patients after different operative techniques for midline incisional hernias and of 12 healthy subjects was studied with the Biodex isokinetic dynamometer. The result of this study included that; the mean torque/weight $(\mathrm{Nm} / \mathrm{kg})$ for trunk flexion was significantly higher in the control group compared to the patient group after incisional hernia repair. He concluded that, the isokinetic strength of the trunk flexor muscles is reduced after an operation for incisional hernia.

The results of the present study were disagreed with Futter et al., [25] who aimed to investigate the effect of pre-operative abdominal exercises on inpatient pain levels, length of hospital stay, postoperative abdominal muscle strength and function following a Deep Inferior Epigastric artery and vein Perforator DIEP flap. The exercise group performed pre-operative exercises using the $\mathrm{Ab}$ dotrim abdominal exerciser. Pre-operatively, outcome measures included trunk muscle strength measured on an isokinetic dynamometer, SF-36, rectus muscle thickness measured using ultrasound, and submaximal fitness. Subjects were reassessed using the same outcome measures 1 year postoperatively. At 1 year, the mean static strength and muscle thickness for the exercise group (which increased as a result of the exercises) tended to increase post-operatively compared to the initial assessment. This is in contrast with the control group, where there was a tendency towards a decrease in both mean static strength and muscle thickness. None of these results were statistically significant, but the indication is that the exercise group may have benefited from the increase in isometric strength achieved as a result of the exercises.

\section{Conclusion:}

It can be concluded that pre-operative abdominal training has significant effect on abdominal muscles strength after ventral hernia repair.

\section{References}

1- KARANJA D.N., KIMELI P., KIPYEGON A.N., MWANGI W.E. and MOGOA E.G.M.: "Diffuse Peritonitis Associated With Ventral Hernia" Journal of Agriculture and Veterinary Science, 7: 53-5, 2014.

2- MUYSOMS F., CAMPANELLI G., CHAMPAULT G.G., DEBEAUX A.C., G.G., S’MIETAN'SKI M. and Miserez M.: "The Development of an International Online Platform for Registration and Outcome Measurement of Ventral Abdominal Wall Hernia Repair" The Journal of Hernia, 16 (3): 239-50, 2012.

3- DI MARZO F.: Inguinal Hernia and Other Types of Hernia: Diagnostic and Therapeutic Approach In: ZINI R., VOLPI P., and BISCIOTTI G.N. (Ed), Groin Pain Syndrome: A Multidisciplinary Guide to Diagnosis and Treatment, (first edition), Milan. Springer, 89-95, 2017.

4- EKER H.H., HANSSON B.M.E., JEEKEL J. and LANGE J.F.: "Laparoscopic vs. Open Incisional Hernia Repair" JAMA. Surg., 148 (3): 259-63, 2013.

5- BATHLA J.A. and FITZGIBBONS R.J.: "Ventral Herniation in Adults" In: PEMBERTON J.H., DAVID W., and YEO C.J. (Ed), Shackelford's Surgery of the Alimentary Tract" (second edition), Philadilphia, Elsevier. Health. Sciences, 600-37, 2012.

6- RAMSHAW B.: "Laparoscopic Ventral Hernia Repair" In: CALLERY M.B., BLAND K.I., and FISHER J.E. (Ed), Master of Surgery, (fifth edition), Boston, Lippincott Williams \& Wilkins, 1985-1976, 2006.

7- HANNA E.M.,VOELLER G.R. and IANNITT D.A.: "Evaluation of ECHO PS Positioning System in a Porcine Model of Simulated Laparoscopic Ventral Hernia Repair" Journal of International Scholarly Research Notices, 20 (11): 562-89, 2013.

8- MERCOLI H., TZEDAKIS S., MEMEO R., MEYER N., VIX M., PERRETTA S. and MUTTER D.: "Postoperative Complications as an Independent Risk Factor for Recurrence after Laparoscopic Ventral Hernia Repair" The Journal of the Society of American Gastrointestinal and Endoscopic Surgeons, 10 (2): 140-6, 2016.

9- STOKMANS R.A., POUWELS S., WILLIGENDAEL E.M. and TEIJINK J.A.: "Preoperative Exercise Therapy for Elective Major Abdominal surgery" The International Journal of Surgery, 12 (2): 134-40, 2014.

10- HOU M.F., LIAW L.J., LIN S.D., GUO L.Y., HOU Y.Y., and HSU A.T.: "Ultrasound Imaging Evaluation of Abdominal Muscles after Breast Reconstruction with a Unilateral Pedicled Transverse Rectus Abdominis Myocutaneous Flap" Journal of the American Physical Therapy Association, 93 (3): 356-68, 2013.

11- KUBER S.: "Hernia Surgery Simplified" (first edition), New Delhi, J.P. Medical Ltd., 5-22, 2013.

12-KNIGHT K.A., MOUG S.J. and WEST M.A.: "The Impact of Exercise on Mesenteric Blood Flow and its Implication for Pre-operative Rehabilitation" Journal of Techniques in Coloproctology, 21 (3): 185-201, 2017. 
13- GEORGE J.A.: "Abdominal Training" (second edition), Indiana, Xlibris. Corporation, 17-31, 2012.

14- ZHENG X.Q.W., SHEN H.M., CHEN Y., PAN Y.J., XU G.H. and CHEN P.J.: "A Meta-Analysis of Core Stability Exercise versus General Exercise for Chronic Low Back Pain" Journal of PublicLibrary of Science, 7 (12): 52082, 2012.

15- SUNDSTRUP E., JAKOBSEN M.D., ANDERSEN C.H., JAY K. and ANDERSEN L.L.: "Swiss Ball Abdominal Crunch with Added Elastic Resistance is an Effective Alternative to Training Machines" International Journal of Sport Physical Therapy, 7 (4): 372-80, 2012.

16- DEN HARTOG D., EKER H., TUINEBREIJER W., KLEINRENSINK G., STAM H. and LANGE J.: "Isokinetic Strength of the Trunk Flexor Muscles after Surgical Repair for Incisional Hernia" Journal of Hernia, 14 (3): 243-7, 2010.

17- TSAOPOULOS D.E., BALTZOPOULOS V., RICHARDS P.J. and MAGANARIS C.N.: "Mechanical Correction of Dynamometer Moment for the Effects of Segment Motion during Isometric knee-extension Tests" Journal of Applied Physiology, 111 (1): 68-74, 2011.

18- SINGHAL V., SZETO P., VANDERMEER T.J. and CAGIR B.: "Ventral Hernia Repair: Outcomes Change with Longterm Follow-up" Journal of the Society of Laparoendoscopic Surgeons, 16 (3): 373-9, 2012.

19- SINGH F., NEWTON R., BAKER M., SPRY N., TAAFFE D. and GALVÃO D.: "Feasibility and Efficacy of Presurgical Exercise in Survivors of Rectal Cancer Scheduled to Receive Curative Resection" Journal of Clinical Color ectal. Cancer, 33 (16): 241-56, 2017.
20- STRIGÅRD K., CLAY L., STARK B., GUNNARSSON U. and FALK P.: "Giant Ventral Hernia Relationship between Abdominal Wall Muscle Strength and Hernia Area", Journal of Bio Medical Central Surgery, 16 (50): 471-82, 2016.

21- MORAN J., GUINAN E., Mc-CORMICK P., LARKIN J., MOCKLER D., HUSSEY J., MORIARTY J. and WILSON F.: "The Ability of Prehabilitation to Influence Postoperative Outcome after Intra-abdominal Operation: A Systematic Review and Meta-analysis" The Journal of Surgery, 160 (5): 1189-201, 2016.

22- POUWELS S., HAGEMAN D., NIENHUIJS S., SCHELTINGA M. and TEIJINK J.: "Pre-operative Exercise Therapy in Surgical Care: A Scoping Review" Journal of Clinical Anesthesia, 33: 476-90, 2016.

23- VALKENET K., VAN DE PORT I., DRONKERS J., DE VRIES W., LINDEMAN E. and BACKX F.: "The Effects of Pre-operative Exercise Therapy on Post-operative Outcome " Clinical Rehabilitation, 25 (2): 99-111, 2011.

24- GUNNARSSON U., JOHANSSON M. and STRIGÅD K.: "Assessmentof Abdominal Muscle Function Using the Biodex System Validity and Reliability in Healthy volunteers and Patients with Giant Ventral Hernia" Journal of Hernia and Abdominal Wall Surgery, 15 (4): 417-21, 2011.

25- FUTTER C.M., WEILER-MITHOFF E., HAGEN S., WEBSTER M.H., HAMDI M. and BLONDEEL P.N.: "Do Pre-operative Abdominal Exercises Prevent Postoperative Donor Site Complications for Women Undergoing DIEP Flap Breast Reconstruction?" Journal of Plastic, Reconstructive \& Aesthetic Surgery, 56 (7): 674 83, 2003.

\section{تأثير تمارين البطن ما قبل جراحة رأب الفتق البطنى

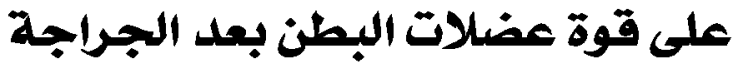

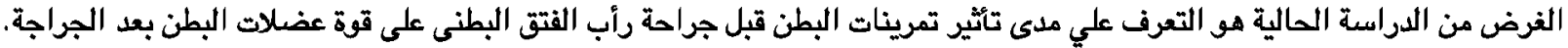

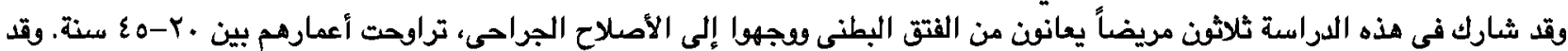

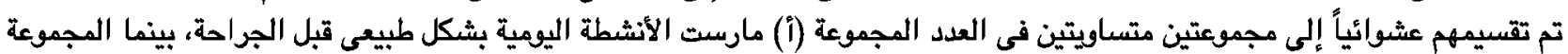

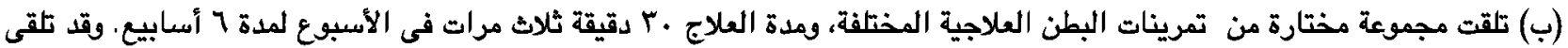

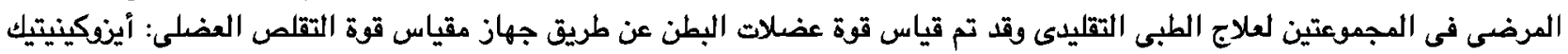

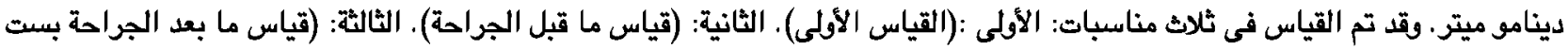

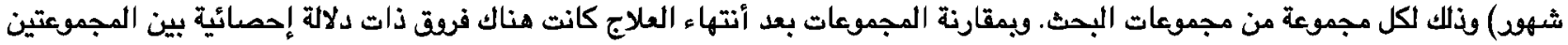

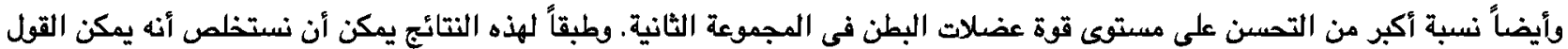

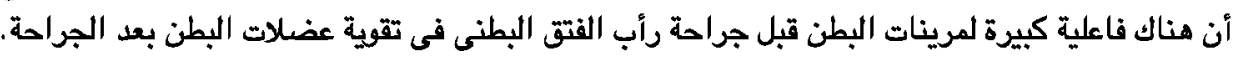

